\title{
A Study of the Properties of Eaton's Primary Atypical Pneumonia Organism
}

\author{
By GILLIAN M. GOODBURN \\ Department of Bacteriology, The University, Leeds 2 \\ AND B. P. MARMION \\ Virus Laboratory, Public Health Laboratory Service, Bridle Path, Leeds 15
}

(Received 8 January 1962)

\begin{abstract}
SUMMARY
Some of the recorded properties of a filterable organism (the PAP organism) isolated by Eaton and colleagues from cases of human primary atypical pneumonia suggest that it may be related biologically to the Mycoplasma (pleuropneumonia-like) group. In further investigation of this possibility now reported it was found that the organic gold salt, sodium aurothiomalate, which is known to inhibit certain mycoplasmas, would also inhibit infection with the PAP organism in the hamster and chick embryo lung. Some accepted viruses of a similar order of size to the PAP organism - namely, Nigg's pneumonitis virus of mice (psittacosis group), three strains of influenza virus $A$, vaccinia and variola viruses-were not inhibited by sodium aurothiomalate. On the other hand, grey lung virus of mice, an organism with some properties resembling those of the PAP organism, was strongly inhibited. Diethyl ether and the antibiotic kanamycin sulphate both inhibited the growth of the PAP organism in chick embryo lung. An intensified Giemsa-staining method revealed small red-purple coccobacillary bodies (later called elementary bodies, EB) in the lungs of chick embryos infected with three different strains of PAP organism isolated, respectively, in 1944, 1954 and 1960 in different parts of the United States. The EB were not seen in uninfected chick embryo lungs. The EB and the antigen of the PAP organism stained by the fluorescent antibody technique occupied essentially the same position in relation to the mesobronchial epithelial cells of chick embryo lung. The formation of both was suppressed in parallel by treatment of inoculum or eggs with diethyl ether, kanamycin sulphate or sodium aurothiomalate. There was a good but not absolute correlation between the presence or absence of EB and antigen in experiments on the growth or survival of the PAP organism in chick embryos, in cell-free media, and in titrations in eggs.
\end{abstract}

\section{INTRODUCTION}

Investigations by several groups of workers in the United States have shown convincingly that one of the varieties of human primary atypical pneumonia, namely that in which some patients develop serum agglutinins against the Streptococcus MG, or against human erythrocytes and active in the cold, is caused by a filterable organism (Eaton's agent or organism; the PAP organism) which can be grown in chick embryo lung or in certain tissue cultures, and produces small areas of pneumonia when inoculated intranasally into cotton rats and hamsters (Eaton, 
Meiklejohn \& Van Herick, 1944; Eaton, $1950 a$; Liu, Eaton \& Heyl, 1956; Chanock et al. 1960; Clyde, Denny \& Dingle, 1960; Cook et al. 1960; Gordon et al. 1960; Chanock et al. 1961). The handling of this organism in the laboratory was greatly eased by finding that its presence in sections of infected chick embryo lung could be demonstrated by the indirect fluorescent antibody technique with antisera either from convalescent patients or from rabbits immunized with infected chick embryo lung (Liu et al. 1956; Liu, 1957).

The nature and identity of the PAP organism has until recently been uncertain. Despite its large particle size (between 180 and $250 \mathrm{~m} \mu$ as measured by filtration through Gradocol membranes (Eaton, 1950a)), it was not seen in smears or sections from infected tissues examined by light microscopy (Eaton \& Liu, 1957). Its growth is not inhibited by sulphonamides and penicillin, but some strains are inhibited by streptomycin; tetracyclines, Carbomycin, erythromycin and aldehyde semicarbazones inhibit all strains so far tested (Eaton, 1950 a; Eaton \& Liu, 1957; Eaton, $1950 b$; Eaton, 1954-55; Eaton, Perry \& Gocke, 1957). Although the size, antibiotic sensitivities and other properties of the organism resemble to some extent those of a rickettsia or a psittacosis group virus there are substantial reasons for supposing that it is neither. Thus: $(a)$ sera from patients with antibody to the organism, or from hyperimmunized rabbits, do not fix complement either with psittacosis group antigen, or with group antigens from murine and epidemic typhus and rickettsialpox, or with phase 1 and 2 antigens from Rickettsia burneti; (b) sera containing antibody against the psittacosis group of viruses and $R$. burneti do not stain by immunofluorescence sections of chick embryo lung infected with the PAP organism; $(c)$ examination of infected tissues from cotton rats, hamsters and chick embryos, including impression smears from yolk sacs infected with the PAP organism in Leeds, has not shown rickettsias or the characteristic elementary particles of the psittacosis group in preparations stained with ordinary Giemsa or rickettsial stains (Eaton, 1950 $a$; Liu, 1957; Goodburn \& Marmion, unpublished).

In 1961 we produced indirect evidence that the organism is not a virus but was related to the pleuropneumonia-like or Mycoplasma group of organisms (Marmion \& Goodburn, 1961; Goodburn \& Marmion, 1962). This view of the organism's identity was also considered as one of several possibilities by Eaton \& Liu (1957). It has recently been substantiated by the cultivation, on cell-free media inoculated with tissue culture fluid infected with one of the standard strains of Eaton's organism, of a Mycoplasma which reacts specifically by immunofluorescence with sera known to contain antibody to Eaton's organism (Chanock, Hayflick \& Barile, 1962).

A comparison of the properties of Eaton's organism and those of certain Mycoplasma is set out in Table 1 . There is, of course, a wide variation of properties within Mycoplasma. The data given are derived from Edward (1947, 1954); Morton (1958), Pollock, Kenny \& Syverton (1960) and Fogh \& Hacker (1960); those on the PAP organism mainly from Eaton et al. (1944), Eaton, Meiklejohn, Van Herick \& Corey $(1945)$, Eaton $(1950 a, b)$, and the other papers already mentioned here. The evidence establishing the properties in brackets in Table 1, described in outline in earlier reports (Marmion \& Goodburn, 1961; Goodburn \& Marmion, 1962), is now presented in detail. 


\section{METHODS}

Strains of Eaton's PAP organism. Three strains isolated in the U.S.A. were used: (1) The 'Hetter' (FH) strain, kindly given to us by Professor C. H. Stuart-Harris (Sheffield), was isolated in Boston in 1954 (Liu, 1957). It was in the form of infected chick embryo (CE) lung suspension and had had at least seven serial passages in

Table 1. A comparison of various properties of Eaton's PAP organism with those of certain members of the Mycoplasma group

\begin{tabular}{|c|c|c|}
\hline & $\begin{array}{c}\text { Eaton's } \\
\text { PAP organism }\end{array}$ & Mycoplasma \\
\hline Size & $180-250 \mathrm{~m} \mu$ & $125-250 \mathrm{~m} \mu$ \\
\hline Light microscopy & $\begin{array}{c}\text { ('Elementary bodies') } \\
\text { EB }\end{array}$ & $\begin{array}{l}\text { Coccobacilliform or } \\
\text { pleomorphic bodies }\end{array}$ \\
\hline $\begin{array}{l}\text { Sensitivity to chemicals } \\
\text { Sulphonamide/penicillin: } \\
\text { Tetracyclines } \\
\text { Erythromycin } \\
\text { Streptomycin } \\
\text { Kanamycin } \\
\text { Organic arsenic compound } \\
\text { Organic gold salt } \\
\text { Diethyl ether }\end{array}$ & $\begin{array}{c}- \\
++ \\
+ \\
+ \text { or }- \\
(++) \\
( \pm) \\
(+) \\
(++)\end{array}$ & $\begin{array}{c}- \\
++ \\
+ \text { or }- \\
+ \text { or }- \\
++ \\
+ \text { or }- \\
+ \\
++\end{array}$ \\
\hline $\begin{array}{l}\text { Type of pneumonia in } \\
\text { animals }\end{array}$ & $\begin{array}{c}\text { Consolidation rarely } \\
\text { complete and very } \\
\text { variable. Serial } \\
\text { transmission very } \\
\text { difficult* }\end{array}$ & $\begin{array}{l}\text { Consolidation rarely } \\
\text { complete and vari- } \\
\text { able. Some diffi- } \\
\text { culty in serial } \\
\text { transmission } \dagger\end{array}$ \\
\hline $\begin{array}{r}\text { Viability } \mathbf{2 0}^{\circ} \\
\mathbf{3 7}^{\circ}\end{array}$ & $\begin{array}{l}\text { About } 4 \mathrm{hr} . \\
\text { About } 6 \mathrm{hr} . \\
\text { (2 to } 12 \text { days) } \ddagger\end{array}$ & $\begin{array}{l}15 \mathrm{~min} \text {. to } 24 \mathrm{hr} . \\
15 \mathrm{~min} \text {. to } 24 \mathrm{hr} \text {. }\end{array}$ \\
\hline $\begin{array}{l}\qquad 5^{\circ} \\
\text { Lifeless media } \\
\text { Chick embryo and tissue } \\
\text { culture }\end{array}$ & $\begin{array}{l}15 \text { min. } \\
\text { Growth } \\
\text { Growth }\end{array}$ & $\begin{array}{l}2 \text { min. } \\
\text { Growth } \\
\text { Variable growth }\end{array}$ \\
\hline
\end{tabular}

- = Growth not inhibited;,,$+++ \pm=$ varying degrees of inhibition of growth; + or - = strains may be sensitive or resistant.

* Lesion in hamster lung.

$\uparrow$ Lesion produced by $M$. pulmonis in mouse lung.

$\$$ Depends on the composition of the medium: see text.

( ) = Established by work described in this paper.

eggs, either in America or in England. (2) The classical 'Mac' strain (subculture Mac 73B) was obtained directly from Boston through the kindness of Dr M. D. Eaton. It was isolated from lung tissue in 1944 (Eaton et al. 1945) and was in the form of infected CE lung suspension; it had had seventy-three serial passages in eggs. (3) The 'Bethesda PI. 898' strain, recently isolated from a case of atypical pneumonia, was kindly given to us by Dr R. M. Chanock (National Institutes of Health, Bethesda, Md., U.S.A.). It had been maintained in primary monkey kidney tissue culture and had not been passed through chick embryos before it arrived in our laboratory. Infected material representing all three strains was stored in ampoules on solid carbon dioxide at $-60^{\circ}$ to $-70^{\circ}$ and was passaged from time to time in chick embryos or tissue culture. 
Chick embryo techniques. Thirteen-day chick embryos were inoculated into the amnion under direct vision via the air sac (Taylor \& Chialvo, 1942). After inoculation the eggs were incubated at $35^{\circ}$ for 6 or 7 days. Without chilling, the embryos were then removed and the lungs harvested by opening the thorax from behind. A portion of each pair of lungs was cultured for bacteria, placed in a bijou bottle and rapidly frozen in a mixture of ethanol + solid carbon dioxide. The frozen lungs were then placed at $-40^{\circ}$ for 24 or $48 \mathrm{hr}$. until the results of culture were known. Those proved sterile were pooled, ground with washed, sterile carborundum powder and mixed with a diluent in the proportion of $1.5 \mathrm{ml}$. for each pair of lungs from one embryo (= a ' $10 \%$ ' suspension). The diluent (EO diluent) consisted of tryptose + phosphate broth (Difco) containing $1 \%(\mathrm{v} / \mathrm{v})$ bovine serum albumin (fraction V, Armour), inactivated at $56^{\circ}$ for $60 \mathrm{~min} ., 0 \cdot 3 \%(\mathrm{w} / \mathrm{v}$ ) gelatin ('Oxoid' high grade bacteriological gelatin) and penicillin (1000 units/ml.). After light centrifugation (2000 rev./min., for $10 \mathrm{~min}$.) the supernatant fluid was placed in ampoules, sealed, quick-frozen in a bath of ethanol + solid carbon-dioxide and stored at $-70^{\circ}$. Lungs from three to six embryos in each batch were examined for infection by a fluorescent antibody technique (immunofluorescence) now described.

Fluorescent antibody technique with infected chick embryo lung. Frozen sections of lung were cut on a Leitz base-sledge microtome held in $-20^{\circ}$ storage cabinet (Prestcold). The specimen-holder of the microtome was modified by replacing the tilting platform with a heavy split brass block into which could be clamped removable brass pegs on to which the CE lungs were frozen. Further cooling was provided by linking the brass pegs, by a copper strip, to a cylindrical brass container filled with chips of solid carbon-dioxide. In addition a perforated container filled with chips of solid carbon-dioxide was placed in the freezing cabinet below the microtome and in the path of a stream of cold air from an electric hair dryer; this cooled the air further and circulated it around the microtome knife and the modified specimen holder. Conditions were adjusted by switching the dryer on or off so as to maintain the required temperature of $-17^{\circ}$ to $-20^{\circ}$ around the knife.

Tissue blocks were prepared by harvesting one lung from a chick embryo, placing it hilum-side upwards in a drop of $15 \%(\mathrm{w} / \mathrm{v})$ aqueous gelatin (Oxoid), buffered to $\mathrm{pH} \mathbf{7 \cdot 4}$, on the surface of a brass peg, protecting it with a collar of tin foil and quickfreezing by immersing the whole of the shaft of the peg in acetone + solid carbondioxide mixture. Sometimes, to save labour in infectivity titrations, up to three lungs from different embryos were orientated in the gelatin solution and then frozen to make a composite block. Sections were cut at about $5 \mu$ and rapidly melted on to microscope slides, previously dipped in $1 \%(w / v)$ aqueous gelatin (Oxoid,

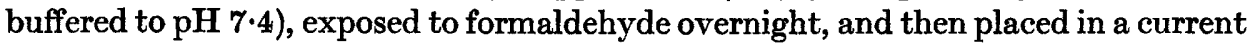
of cold air from the hair dryer for at least $2 \mathrm{hr}$. to remove traces of formaldehyde.

Some sections of CE lung were used unfixed, but most were fixed for $10 \mathrm{~min}$. in Analar-grade acetone (previously held over anhydrous calcium sulphate) then dried on to the slides for $60 \mathrm{~min}$. in a stream of cold air from the hair dryer and stored at $4^{\circ}$ or $-20^{\circ}$ until stained. In general the best results were obtained when lungs were harvested and cut on the same day. Single sera, or pools of human convalescent sera from local cases of atypical pneumonia which had a high or rising titre of Streptococcus MG agglutinins, or serum from a rabbit immunized by repeated 
intraperitoneal injections of CE lung suspension infected with the Hetter strain, were used as the middle layer in the indirect fluorescent-antibody technique. For the detection of antigen in sections the sera were diluted, just before use, to a concentration 10 or 20 times greater than that just reacting in previous titrations on infected chick embryo lungs by immunofluorescence, then absorbed twice with liver and lung powder from mice and chick embryos. About two drops of this diluted serum were mixed with one drop of a 1/10 dilution of guinea-pig serum (fresh or preserved by Richardson's (1941) method) in saline (to provide the necessary co-factors for staining) and placed on the chick embryo lung sections so as to cover them completely and uniformly. Dilutions of serum for antibody titrations were made in saline containing $10 \%(\mathrm{v} / \mathrm{v})$ guinea-pig serum and $0.2 \mathrm{ml}$. of each serum dilution transferred to a series of sections. The slides were placed in a moist chamber at $37^{\circ}$ for $60 \mathrm{~min}$. and then washed with three changes of phosphatebuffered saline ( $\mathrm{pH} \cdot 7 \cdot 4)$. The sections were then covered with a suitable dilution, previously determined by titration on positive sections, of fluorescein-labelled antihuman or antirabbit globulin; obtained initially from Sylvana Chemical Co. N.J., U.S.A., or Microbiological Associates, Bethesda, Md., U.S.A., and later prepared here with fluorescein isothiocyanate from G. T. Gurr (London) and antiglobulins from Dr W. Goldie (Leeds) or from Burroughs Wellcome and Co. Ltd. (London). The diluted conjugates were absorbed twice with the liver powders and once with activated charcoal (about $5 \mathrm{mg}$./ml.).

After further incubation at $37^{\circ}$ for 30 min. and three washes with phosphatebuffered saline the sections were mounted in glycerol (Analar) buffered to $\mathrm{pH} \mathrm{7 \cdot 4,}$ and the coverslips sealed with colourless nail varnish. On examination in the ultraviolet microscope the characteristic intense fluorescence described by Liu et al. (1956) was seen in association with epithelial cells of the mesobronchi and, more rarely, in small patches in the parabronchi.

Ultraviolet microscope. The optical system was constructed here and consisted of a high-pressure mercury vapour lamp (Mazda ME/D, 250 W., 20,000 stilbs), a glass condensing lens, a $3 \mathrm{~cm}$. thick Perspex box containing $5 \%(\mathrm{w} / \mathrm{v})$ aqueous copper sulphate $\left(\mathrm{CuSO}_{4} .5 \mathrm{H}_{2} \mathrm{O}\right)$ and a $2 \mathrm{~mm}$. thick Chance glass filter no. OX 1 (Pilkington Bros. Ltd., Wales). The light coming through this system was focused directly on to the substage of a Bactil microscope (Watson Ltd., London) with a reflecting dark-ground condenser. Non-fluorescent-immersion oil ('Fluor-free'; G. T. Gurr, London) was used between the condenser and the slide. Either a pale yellow gelatin filter, Aviol 102 (Ilford, Ltd., London) or a Chance glass OY 18 (Pilkington Bros. Ltd., Wales) was placed in a $\times 8$ ocular held in a Bactil monocular tube.

Hamster inoculations. Infected chick embryo lung suspensions were also tested by intra-nasal inoculation of hamsters. Hamsters $(60-90 \mathrm{~g}$.) were lightly anaes-

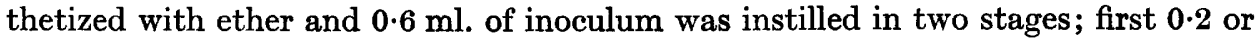
$0.4 \mathrm{ml}$., then fresh anaesthesia and the instillation of the residue. The hamsters were not very susceptible to Eaton's organism and the macroscopic lung lesions were relatively slight and showed great animal-to-animal variation by comparison with those, for example, produced by influenza virus. More impressive changes were seen on microscopical examination; for this purpose the lungs were fixed in $10 \%(\mathrm{v} / \mathrm{v})$ formaldehyde saline, sectioned in paraffin wax and stained with haematoxylin and eosin. 
Mouse inoculations. White mice (Schofield $12 / 1 \mathrm{~A} ; 18-22$ g.) were lightly anaesthetized with ether + chloroform and given $0.1 \mathrm{ml}$. of inoculum intranasally in the experiments with influenza, grey lung and Nigg's pneumonitis viruses.

\section{RESULTS}

Organic gold preparations are known to have an inhibitory effect on infections with some pleuropneumonia-like organisms; for example on pneumonia or arthritis in mice caused, respectively, by Mycoplasma pulmonis and Mycoplasma arthritidis (Edward, 1947; Findlay, Mackenzie \& MacCallum, 1940; Sabin \& Warren, 1940). Their action on virus infections does not seem to have been investigated very extensively, but Jungeblut (1930-31), Kolmer \& Rule (1933-34) and Andrewes, King \& van den Ende (1943) found that poliomyelitis virus in monkeys and influenza $A$ and lymphogranuloma (LGV) viruses in mice were not inhibited. Bauer (1958) found that an inorganic gold salt did not inhibit neurovaccinia in mice. The effect of sodium aurothiomalate on infections with two strains of Eaton's PAP organism, and with certain large viruses of a similar size was investigated in hamsters, mice and chick embryos.

\section{Effect of sodium aurothiomalate on Eaton's PAP organism}

Experiments with the PAP organism in hamsters. Groups of hamsters were inoculated intra-nasally with ' $10 \%$ ' CE lung infected with the Hetter (FH) strain of PAP organism. About half the animals were given a daily intraperitoneal injection of 3.0 or $5.0 \mathrm{mg}$. of sodium aurothiomalate (Myocrysin; May and Baker) for 12 or 13 days. This was a dose of $4-8 \mathrm{mg}$., average of $5 \mathrm{mg}$. $/ 100 \mathrm{~g}$. hamster body weight. The remaining animals were either not injected, or were injected with the same volume of distilled water containing 1/5000 phenylmercuric nitrate (a preservative present in the preparation of sodium aurothiomalate used). Twelve or thirteen days after inoculation the animals were killed with coal-gas and their lungs assessed for the extent of macroscopic and microscopic lesions. The range of macroscopic scores was $0.5=$ a few small (about 1-2 mm. diam.) grey pneumonic areas in one or other lung; $1.0=$ moderate numbers of grey areas in both lungs; $2 \cdot 0=$ numerous grey areas in both lungs; $\mathbf{3} \cdot 0=$ numerous grey areas in both lungs together with one larger area of frank red consolidation in either lung; $4 \cdot 0=$ numerous grey areas both lungs, together with two or more larger areas of red consolidation. The microscopic lesion scores depended on: $(a)$ proportion of bronchi and vessels with cuffs of mononuclear cells seen in the section and was assessed in five units representing 10-100\% 'cuffing' of the bronchi and vessels; $(b)$ a 3-unit assessment of the extent of alveolar consolidation. The sum of these two scores gave the total for the section, the maximum being 8:0. Average lesion scores were calculated by dividing the total score by the number of hamsters in the group.

A total of 56 hamsters (27 gold-treated; 29 controls) were used in four separate experiments with the Hetter strain. Table 2 shows the frequency distribution of the individual macroscopic and microscopic lesion scores in the total group of 56 hamsters and also the average lesion scores obtained in each of the four experiments. Despite the small extent of the visible lesions there was a clear-cut and significant difference between the overall results for the gold-treated and control groups, and 
the suppression of lesions was consistent in each of the four experiments. Analysis showed that the differences between treated and untreated groups were unlikely to have arisen by chance alone; for macroscopic lesions $\chi^{2}=31 \cdot 5$, D.F. $=5, P<0 \cdot 001$ for microscopic lesions $\chi^{2}=53 \cdot 3$, D.F. $=8, P<0 \cdot 001$. Table 2. Intensity of lung lesions in gold-treated and untreated hamsters
infected with Eaton's $\boldsymbol{P A P}$ organism

\begin{tabular}{|c|c|c|c|c|c|c|c|c|c|c|}
\hline & \multicolumn{9}{|c|}{$\begin{array}{l}\text { Number of hamsters with lung lesion score of } \\
\text { (macroscopic) }\end{array}$} & \multirow{2}{*}{ Total } \\
\hline & & & 4 & $\mathbf{3}$ & 2 & $\mathbf{1}$ & 0.5 & $\mathbf{0}$ & & \\
\hline \multirow{4}{*}{$\begin{array}{l}\text { Controls } \\
\text { Gold-treated }\end{array}$} & & & 2 & 4 & 9 & 7 & 5 & 2 & & 29 \\
\hline & & & 0 & $\mathbf{0}$ & $\mathbf{0}$ & $\mathbf{1}$ & 9 & 17 & & 27 \\
\hline & \multicolumn{9}{|c|}{$\begin{array}{l}\text { Number of hamsters with lung lesion score of } \\
\text { (microscopic) }\end{array}$} & \\
\hline & 8 & 7 & 6 & 5 & 4 & $\mathbf{3}$ & 2 & 1 & $<1$ & \\
\hline Controls & $\mathbf{3}$ & $\mathbf{3}$ & 5 & 12 & 5 & $\mathbf{1}$ & 0 & $\mathbf{0}$ & $\mathbf{0}$ & 29 \\
\hline Gold-treated & $\mathbf{0}$ & $\mathbf{0}$ & 0 & $\mathbf{0}$ & $\mathbf{0}$ & 2 & 5 & 15 & $\mathbf{5}$ & 27 \\
\hline
\end{tabular}

The average macroscopic (MC) and microscopic (mc) lesion scores in the four experiments were, respectively: controls $\mathrm{MC}=1.5,1.6,1.7$ and $1.6 ; \mathrm{mc}=4.6,6.0,5.8$ and 4.9 ; gold-treated $\mathrm{MC}=0.25,0 \cdot 14,0.3$ and $0.07 ; \mathrm{mc}=1.5,1 \cdot 0,1 \cdot 2$ and $1 \cdot 1$.

Table 3. Frequency distribution of the fluorescent intensities of specific antigen of Eaton's $\boldsymbol{P A P}$ organism in chick embryos treated with sodium aurothiomalate and their controls

Material given via the yolk sac

Sodium aurothiomalate Sterile diluent or phenylmercuric nitrate
Number of chick embryos with a specific fluorescence of an intensity

$\begin{array}{rrrrrc}- \text { or } \pm & + & ++ & +++ & ++++ & \text { Total } \\ 32 & 3 & 2 & 1 & 0 & 38 \\ 5 & 14 & 18 & 8 & 2 & 47\end{array}$

Some chick embryos were inoculated via the yolk sac with a single dose of sodium aurothiomalate and others with inert diluent or phenylmercuric nitrate. The Hetter strain of PAP organism was inoculated into the amnion of all embryos. Six or seven days later lungs were stained with the human convalescent serum pool and fluorescein-labelled antihuman globulin. Variable numbers of mesobronchi were present in the lung sections and a mean value for the intensity was derived from them for the embryo as a whole.

A similar experiment with the Bethesda PI. 898 strain in hamsters also showed that sodium aurothiomalate inhibited the lung lesions. The average lesion scores, macroscopic $(\mathrm{MC})$ and microscopic $(\mathrm{mc})$ were: untreated $\mathrm{MC}=2 \cdot 1, \mathrm{mc}=3 \cdot 3$; gold-treated $\mathrm{MC}=0.39, \mathrm{mc}=0.8$ and for animals given inoculum mixed with human antiserum to the PAP organism: $M C=0 \cdot 46, \mathrm{mc}=0.5$.

Sodium aurothiomalate appeared mainly to decrease the perivascular and peribronchial infiltration with mononuclear cells; small focal cellections of polymorphonuclear leucocytes were still present in the treated animals. As the gold salt might have limited the tissue reaction, rather than the multiplication of the PAP organism, attempts were made to find out whether gold salts would also act on the organism in the chick embryo, in which it grows without much tissue reaction. 
Experiments with $\boldsymbol{P A P}$ organism in chick embryos. In these experiments 12- or 13-day chick embryos were inoculated in the yolk sac with a single dose of 25 or $30 \mathrm{mg}$. sodium aurothiomalate. On the same or next day, the eggs were inoculated amniotically with a $1 / 10$ to $1 / 500$ dilution of $10 \%$ Hetter-infected CE lung suspension as appropriate. Control eggs received the same volume of sterile diluent or 1/5000 phenylmercuric nitrate into the yolk sac and then the infected CE lung suspension into the amnion. The treated and control eggs were then incubated for 6 or 7 days, the lungs harvested, sectioned and examined for antigen by the fluorescent antibody technique, and also stained by an intensified Giemsa staining technique described below.

There was a fairly high mortality among the chick embryos which had been given sodium aurothiomalate, and this made it necessary to inoculate large batches of eggs to ensure enough survivors for examination. Eight separate experiments were performed in which 85 embryos were examined, 38 in the group given gold and 47 in the controls. Six $(15 \cdot 8 \%)$ of the 38 treated embryos and $42(89 \cdot 4 \%)$ of the 47 controls had antigen detected by immunofluorescence in one or more mesobronchi at an intensity of + or greater $\left(\chi^{2}=43 \cdot 1\right.$, D.F. $\left.=1, P<0.001\right)$. Table 3 shows a further analysis of the distribution of the intensities of the antigen by immunofluorescence in the 85 treated and control embryos. Unstained or feebly staining mesobronchi were significantly more frequent in the lungs of gold-treated embryos. In two experiments the unsectioned embryo lungs were pooled in two appropriate groups and inoculated into hamsters intra-nasally to obtain independent confirmation of a difference in the content of PAP organism in treated and untreated embryos. The average macroscopic lung lesion scores were, respectively, 0.04 and 0.1 for suspensions from gold-treated embryos, and 1.2 and 2.0 for those from the untreated control embryos.

In vitro effect of sodium aurothiomalate on the PAP organisms. Portions of ' $10 \%$ ' CE lung suspension infected with the Hetter strain were mixed either with sodium aurothiomalate to a final concentration of $1.0 \mathrm{mg} . / \mathrm{ml}$. suspension, or with EO diluent. The mixtures were held at room temperature for $60 \mathrm{~min}$. then subjected to two cycles of centrifugation at $10,000 \mathrm{rev} . / \mathrm{min}$. in the angle head of a refrigerated centrifuge. The deposits from the last centrifugation were suspended in half the original volume of $\mathrm{EO}$ diluent and tested in chick embryos by the standard method. Treatment with the gold salt diminished but did not abolish the capacity of the suspension to produce specific antigen in the chick embryo lung. It was concluded that the gold salt has only a slight direct effect on the organism or that contact over a long period is required for its action.

\section{Effect of sodium aurothiomalate on other viruses}

The significance of the effect of organic gold on the PAP organism would be enhanced if accepted viruses of a similar size were not inhibited when tested under our conditions. The organisms chosen were a virus of the psittacosis group causing pneumonia in mice (Nigg \& Eaton, 1944), three strains of influenza virus A, vaccinia, and variola (alastrim) viruses. Grey lung virus of mice (Andrewes \& Glover, 1945) was also examined because it is a large organism of uncertain identity and because it resembles the PAP organism in its sensitivity to tetracyclines. Also grey lung 
virus has been shown to be inhibited by organic tri- and pentavalent arsenicals (Andrewes \& Niven, 1953), a property shared with certain pathogenic bovine, ovine and caprine Mycoplasma organisms (Bridré, Donatien \& Hilbert, 1928; Mornet, Orue \& Marty, 1951). The results obtained were as follows.

Table 4. Mortalities, mean day of death and mean lung lesion scores in groups of mice inoculated with mouse pneumonitis virus (Nigg) and treated with sodium aurothiomalate or left as controls

\begin{tabular}{|c|c|c|c|c|c|c|}
\hline \multirow[b]{2}{*}{ Inoculum* } & \multicolumn{3}{|c|}{ Gold-treated } & \multicolumn{3}{|c|}{ Untreated } \\
\hline & Mortality $\dagger$ & $\begin{array}{l}\text { Mean day } \\
\text { of death }\end{array}$ & $\begin{array}{c}\text { Extent of } \\
\text { lung lesion } \\
\text { in survivors } \ddagger\end{array}$ & Mortality $\dagger$ & $\begin{array}{l}\text { Mean day } \\
\text { of death }\end{array}$ & $\begin{array}{c}\text { Extent of } \\
\text { lung lesion } \\
\text { in survivors }\end{array}$ \\
\hline 250 & $6 / 6$ & $2 \cdot 6$ & - & $6 / 6$ & $2 \cdot 1$ & - \\
\hline $12 \cdot 5$ & $6 / 6$ & $5 \cdot 3$ & - & $5 / 6$ & $5 \cdot 0$ & - \\
\hline $4 \cdot 0$ & $9 / 15$ & $9 \cdot 7$ & 75 & $8 / 15$ & $9 \cdot 2$ & 65 \\
\hline
\end{tabular}

* Dose in multiples of that producing a lesion involving $50 \%$ or more of the lung in half the mice inoculated.

$\dagger$ Number dead/total mice inoculated.

¥ Sum of individual lung lesion scores, assessed as percentage of lung consolidated at autopsy 12 days after inoculation, divided by the number of survivors in the group.

Table 5. The effect of sodium aurothiomalate on the lung lesions produced by grey-lung virus of mice

\begin{tabular}{|c|c|c|c|c|c|c|}
\hline \multirow[b]{2}{*}{ Inoculum* } & \multicolumn{3}{|c|}{ Gold-treated } & \multicolumn{3}{|c|}{ Controls } \\
\hline & Lesion scores $\dagger$ & $\begin{array}{c}\text { Mean } \\
\text { score } \ddagger\end{array}$ & $\begin{array}{c}\text { Mean } \\
\text { weight§ }\end{array}$ & Lesion scores $\nmid$ & $\begin{array}{c}\text { Mean } \\
\text { score }\end{array}$ & $\begin{array}{c}\text { Mean } \\
\text { weight\$ }\end{array}$ \\
\hline 10,000 & $0,0,0,0 \cdot 5,1,2$ & 0.5 & 246 & $2,3,3,4,4,4$ & $\mathbf{3} \cdot \mathbf{3}$ & $\mathbf{5 7 0}$ \\
\hline 1,000 & $0,0,0,0,0 \cdot 5, D, D, D$ & 0.01 & 269 & $2,2,3,3,3,3,3,4$ & $\mathbf{2} \cdot \mathbf{8}$ & 610 \\
\hline 100 & $\mathbf{0}, \mathbf{0}, \mathbf{0}, \mathbf{0}, \mathbf{D}, \mathbf{D}$ & 0.0 & 314 & $2,3,3,4,4,4$ & $\mathbf{3} \cdot \mathbf{3}$ & 612 \\
\hline
\end{tabular}

* Dose in multiples of that required to produce a lung lesion in half the mice inoculated.

$\uparrow$ Extent of pneumonia : $4=$ typical lesion involving $90 \%$ or more of the lungs; $0=$ no visible lesion; $\mathbf{0} \cdot 5-3=$ intermediate degrees of involvement; $D=$ mouse died during the experiment.

\$ Sum of lesion scores divided by total number examined.

$\S$ Corrected mean weight (mg.) of lungs in the group: see text.

Nigg's mouse pneumonitis virus. Groups of mice were inoculated intra-nasally with dilutions of a lung suspension from mice infected with a strain of Nigg's virus. Some groups were given, daily for 12 days, intraperitoneal injections of $2 \cdot 0 \mathrm{mg}$. sodium aurothiomalate; others were left as controls. The dose of sodium aurothiomalate was proportionately greater than that given to the hamsters (about $10 \mathrm{mg}$.) $100 \mathrm{~g}$. body weight of mouse) but it did not cause death or lung lesions in uninoculated mice. The results (Table 4) show that treatment with gold did not significantly prolong the survival time, decrease the mortalities or alter the mean values for pneumonic consolidation in the mice which survived to the twelfth day after inoculation.

Grey lung virus. Groups of mice were inoculated intra-nasally with dilutions of lung suspension from mice infected with a strain of grey lung virus from the National Institute for Medical Research, Mill Hill. Some groups were given a daily intraperitoneal dose of $\mathbf{2} \mathrm{mg}$. sodium aurothiomalate, others a dose of phenyl- 
mercuric nitrate equivalent to that in the solution of sodium aurothiomalate used. After 14 days treatment the mice were killed and their lungs examined. In the treated mice there was a striking decrease in the degree of consolidation, in the mean weights and the size of the lungs and also in the amount of fluid exuding from the trachea (Table 5). The pneumonia caused by the virus is diffuse and it is sometimes difficult to judge by eye minor degrees of difference between lungs. For this reason each pair of lungs was weighed to obtain an estimate of consolidation and contained fluid. The treated and untreated groups of mice had increased in total body weight at different rates during the 14 days after inoculation so the weights of the excised lungs were corrected to a standard body weight (20 g. mouse) and the mean values calculated for each group (Table 5). A repetition of the experiment gave the same results.

Influenza viruses. Experiments with mice were done with the mouse-adapted line of the Barratt strain of influenza virus A. Mice were inoculated intra-nasally with allantoic fluid infected with virus and some were given $2 \mathrm{mg}$. sodium aurothiomalate daily for 10 days. There were no striking effects on mortality or lung lesion score, or in prolonging survival time in the treated mice as compared with controls. Experiments in chick embryos were done with the WSE strain of influenza A (Burnet, 1936) and with a strain of influenza A2 (Asian) virus. Ten- or eleven-day chick embryos were given a single dose of $25 \mathrm{mg}$. sodium aurothiomalate into the yolk sac either 2 days before or at the same time as allantoic inoculation with the influenza virus. Three days later the allantoic fluids were harvested and the haemagglutinins titrated. When very small doses of influenza virus (about 4 EID50 doses) were used there was some decrease of mean haemagglutinin titre in the allantoic fluids from the gold-treated embryos as compared with the controls, but this effect was not observed with larger inocula (e.g. 400 EID 50 doses).

Vaccinia and variola viruses. Ten-day chick embryos received a single dose of $25 \mathrm{mg}$. sodium aurothiomalate, or of phenylmercuric nitrate, equivalent to that in the sodium aurothiomalate used into the yolk sac. One or two days later the embryos were inoculated on the chorioallantoic membrane with a dose of vaccinia or variola (alastrim) virus sufficient to produce 15 to 20 pocks. After further incubation ( 2 days for vaccinia, 3 days for variola) the chorioallantoic membranes were harvested and the pocks counted. There was no significant difference in pock counts between the gold-treated and control embryos with either virus.

\section{Effect of miscellaneous substances on Eaton's $\boldsymbol{P} A \boldsymbol{P}$ organism}

Andrewes \& Niven (1953) found that neoarsphenamine and tryparsamide suppressed the lesions of grey lung virus in mice but had no action on Nigg's virus. In view of our results with sodium aurothiomalate and grey lung virus, the action of neoarsphenamine (Novarsenobillon, May and Baker) on the PAP organism was ascertained. Three groups of hamsters were inoculated intra-nasally with the Hetter strain of PAP organism: one group was given eight daily intraperitoneal doses of neoarsphenamine $(5.5 \mathrm{mg} . / 100 \mathrm{~g}$. body weight); the second was given sodium aurothiomalate $(6 \cdot 1 \mathrm{mg} . / 100 \mathrm{~g}$. body weight); the third was left as a control. Eleven days after inoculation the animals were killed and the lesion scores were: neoarsphenamine mean macroscopic $(\mathrm{MC})$ score $=0.6$, mean microscopic score 
$(\mathrm{mc})=3 \cdot 0 ;$ aurothiomalate, $\mathrm{MC}=\mathbf{0} \cdot 5, \mathrm{mc}=0.7$; controls, $\mathrm{MC}=\mathbf{2} \cdot \mathbf{0}, \mathrm{mc}=4 \cdot 7$. There was, therefore, some inhibitory effect on the lung lesions with the neoarsphenamine, but it was not as striking as with the sodium aurothiomalate.

A ' $10 \%$ ' suspension of CE lung suspension infected with the Hetter strain was mixed with anaesthetic grade diethyl ether in a final concentration of $20 \%(\mathrm{v} / \mathrm{v})$ ether. The mixture and an untreated portion of suspension were held at room temperature for $1 \mathrm{hr}$. and then at reduced pressure to remove the ether. The suspensions were then inoculated into chick embryos in the usual way. Ether-treatment abolished the capacity of the suspension of PAP organism to form specific antigen as detected by immunofluorescence.

A single dose of kanamycin sulphate ('Kannasyn', Bayer), equivalent to 5.0 mg. kanamycin base, placed in the yolk sac of chick embryos one day before amniotic inoculation with the Hetter strain, completely inhibited specific antigen formation.

\section{The elementary particle of Eaton's PAP organism}

Despite the large size of the PAP organism, Eaton and colleagues were unable to demonstrate elementary bodies in smears or sections from various infected tissues by using a variety of stains and the light microscope (Eaton, 1950 $\mathrm{a}$; Eaton \& Liu, 1957). Later Liu (1957) with a knowledge of the exact position of the antigen demonstrable by immunofluorescence found that in histological sections the cells of the chick embryo mesobronchial epithelium appeared to be normal with intact cilia. Donald \& Liu (1959) examined ultra-thin sections of infected CE trachea in the electron microscope and found particles of a diameter of 150-250 $\mathrm{m} \mu$ with thin envelopes of $300 \mathrm{~m} \mu$ in diameter, and some larger structures inside about $10 \%$ of the non-ciliated epithelial cells.

In the early stages of our work with the PAP organisms we stained, by the standard overnight Giesma method, frozen sections of CE lung prepared for fluorescent antibody staining. There was some faintly stained red particulate material close to the surface of the mesobronchial epithelial cells in these sections. To see more clearly we used an intensified Giemsa staining method, based on the observation of Henneguy (1891) that treatment of sections with a solution of permanganate greatly increased the absorption of any stain used subsequently; according to Professor A. W. Downie this technique was probably first applied to Giemsa staining by $\mathbf{P}$. Bruce White. Frozen sections (about $5 \mu$ ) of infected CE lung were fixed in dehydrated acetone for $10 \mathrm{~min}$., removed and allowed to dry. They were then covered with freshly prepared potassium permanganate solution (10 g./1.) for 2 min., washed with distilled water and placed face downwards for $18 \mathrm{hr}$. in a solution of 1/25 Giemsa stain (Improved Giemsa stain, R66, G. T. Gurr, London)

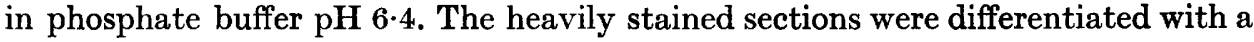
dilute acetic acid ( $5 \mathrm{~g}$./1. water) until there was a clear distinction under the microscope between the nuclei and cytoplasm of the epithelial cells in the mesobronchi. The sections were then washed in distilled water and mounted as wet preparations in a mixture of glycerol + phosphate buffer ( $\mathrm{pH} 6 \cdot 4)$; the coverslips were sealed with colourless nail varnish. Such preparations were best examined quickly; more permanent ones could be made by taking the sections through acetone, xylene, and then mounting in polystyrene $(\mathrm{DePeX})$, but there was a greater proportion of 
failures due to decolorization and distortion. This staining procedure revealed numerous minute pink and purple bodies in association with epithelial cells of the mesobronchi. The bodies were coccoid, or coccobacillary and resembled the coccobacilliform bodies found in exudates from avian infectious coryza. This morphological similarity is not enough, of course, to prove that they are the same sort of organism; at this stage the non-committal term elementary bodies (EB) will be used to denote them.

A few EB were seen lying free in the lumena of the mesobronchi and some were unequivocally within the basophilic cytoplasm of the epithelial cells, but the majority appeared to be extracellular and arranged in a compact layer on the surface of the epithelial cells and largely within a layer of eosinophilic mucus which overlies these cells. This mucous layer was identified by its property of staining blue with Alcian blue at pH 3.0 and red by the periodic acid Shiff celestin-blue haemalum method (Pearse, 1960; it was necessary to prolong the staining times). The bacillary shape of the EB often gave a striking and distinctive palisade-like appearance to the surface of the epithelial cells. The mesobronchial epithelial cells were sometimes fragmented and the cell cytoplasm more contracted and basophilic than that of uninfected controls, but there was no visual evidence either of nuclear inclusions or of organized intracytoplasmic microcolonies of EB. The EB appeared to occupy the same general position in the CE lung as did the specific antigen-that is, they were present in the greatest numbers at the surface of the epithelial cells of the mesobronchi and were usually absent from the parabronchi. Pl. 1, figs. 1 and 2, show the location of EB and specific antigen in an invagination of a mesobronchus in adjacent section from a CE lung infected with the Hetter strain. The angle enclosed by the cell-lined inlet is not quite the same in the two sections because the two staining processes produce different physical effects. Nevertheless it will be seen that the positions of antigen and EB correspond very closely. Examination of adjacent serial sections by the two methods rather than staining the same section, first by immunofluorescence then with Giemsa, was necessary because the EB seemed to be very fragile. Variations in fixing and Giemsa-staining techniques were not investigated exhaustively, but the following points seem important: sections should be mounted on gelatinized slides not directly on glass; acetone, absolute ethanol and possibly Bouin's solution are satisfactory fixatives, but formol saline and Palade's osmium tetroxide cause great distortion and loss of EB; unfixed sections may be used, and treatment with stronger permanganate solution ( $20 \mathrm{~g} . / \mathrm{l}$. water) may be advantageous. Different preparations of Giemsa stain varied in their ability to stain EB.

Typical palisades of EB on the mesobronchial epithelial cells were not seen in any of numerous sections of lung of uninoculated chick embryos (P1. 1, fig. 3) or in those from an experiment in which nine serial blind lung-to-lung passages were made starting from embryos inoculated with sterile EO diluent. On the other hand, EB and antigen were found in many sections from eggs inoculated during routine passage of the Hetter strain of PAP organism. The results of some examinations of embryos, uninoculated or inoculated with negative material, and of infected embryos are combined in Table 6, section $(a)$, which shows that there was a good but not absolute correlation between the presence or absence of the two entities. Sodium aurothiomalate, which decreased the amount of specific antigen in CE lung (Table 3) 
also decreased the number of EB seen in lung sections. Table 6, section $(b)$ summarizes the results from 67 gold-treated and untreated embryos examined by both methods; once again there was a good correlation between the values for antigen and EB. Mesobronchi in the lungs of gold-treated embryos sometimes contained clumps of organisms resembling EB but swollen into larger spheres or long rods. Similarly, examination of sections from embryos inoculated with the Hetter seed and treated with kanamycin, or inoculated with Hetter seed previously treated with diethyl ether (see above), showed that formation of EB was suppressed in parallel with that of specific antigen.

Table 6. Correlations observed between the presence and intensity of specific antigen, and presence and numbers of $\mathbf{E B}$ found by intensified Giemsa staining in chick embryo lungs

Section $(a)$ of the table shows the results for a group of 150 embryos comprising uninoculated normals, those from serial passages of normal CE lung and material from tissue culture experiments and isolation specimens, and from routine serial passage of the Hetter strain of Eaton's PAP organism. Section $(b)$ gives the results for 67 treated and control embryos in the 8 experiments on the effect of sodium aurothiomalate on the growth of the PAP organism in eggs.

In all experiments, replicate sections of $\mathrm{CE}$ lung were stained with a pool of human convalescent sera and fluorescein labelled anti-human globulin, or by the intensified Giemsa method.

Section (a). Embryos inoculated with various positive and negative materials excluding those in experiments on the effect of gold treatment.

$\begin{array}{crcc}\begin{array}{c}\text { Intensity of } \\ \text { fluorescence of specific } \\ \text { antigen in bronchi }\end{array} & \begin{array}{c}\text { Quantity of Giemsa- } \\ \text { stained EB in bronchi }\end{array} \\ - \text { to } \pm & + \text { to } \\ + \text { to } \pm & 96 & 2 & 98 \\ + \text { to }++++ & 7 & 45 & 52 \\ \text { Totals } & 103 & 47 & 150\end{array}$

Section (b). Embryos inoculated in experiments on the effect of gold treatment in eggs.

$\begin{array}{crcc}\begin{array}{c}\text { Intensity of } \\ \text { fluorescence of specific } \\ \text { antigen in bronchi }\end{array} & \overbrace{- \text { to } \pm}^{\begin{array}{c}\text { Quantity of Giemsa- } \\ \text { stained EB in bronchi }\end{array}} \begin{array}{c}+ \text { to } \\ ++++\end{array} & \text { Totals } \\ - \text { to } \pm & 29 & 4 & 33 \\ + \text { to }++++ & 6 & 28 & 34 \\ \text { Totals } & \mathbf{3 5} & 32 & 67\end{array}$

The time of formation of antigen and EB was determined by inoculating embryos with the Hetter strain and harvesting lungs at intervals. Neither antigen nor EB were present in lungs harvested $3 \mathrm{hr}$. after inoculation. At 3 days after inoculation a fine layer of antigen was present but EB were not identified with certainty although a few spherical particles larger than EB were seen. At 4 days antigen had increased and EB were definitely present; both increased in parallel up to the sixth day.

Direct proof that specific antigen and EB are two attributes of the same (PAP) organism would be afforded by neutralizing their formation in chick embryos by 
mixing antiserum with the inoculum. However the results of attempts to do this were equivocal; antiserum did not substantially decrease antigen formation. Eaton et al. (1945) noted that it was difficult to neutralize the PAP organism in chick embryo lung in contrast to the ease with which lesions were neutralized in the hamster or cotton rat lung. However, in the present experiments EB in the lungs of embryos which had received the Hetter strain mixed with antiserum appeared to be swollen, elongated and more variable in size than those in the lungs of the controls; this effect was similar to, but not as striking as, that seen in the goldtreated embryos.

The conditions under which strains of PAP organism have to be propagated (serial egg passage in high concentrations of penicillin) are ideal for permitting contamination with the less pathogenic avian mycoplasma organisms or for inducing $\mathrm{L}$ forms of contaminating bacteria. Indeed Van Herick \& Eaton (1945) describe one episode in which their chick embryo line of PAP organism was contaminated with a pathogenic avian Mycoplasma. The possibility was considered therefore that EB might be units of a contaminating Mycoplasma organism or of a bacterial $L$ form which were being passaged along with the PAP organism. In a test of the possibility two portions of a $1 / 5$ dilution of $10 \% \mathrm{CE}$ lung suspension infected with the Hetter strain were mixed with $(a)$ a $1 / 5$ dilution of pooled convalescent sera from cases of pneumonia with a high titre of antibody to the PAP organism, and (b) $1 / 5$ dilution of human serum which did not contain antibody to the organism. Both sera were diluted in saline containing $10 \%(\mathrm{v} / \mathrm{v})$ guinea-pig serum to provide complement. The mixtures were incubated at $37^{\circ}$ for $30 \mathrm{~min}$. and then inoculated into sloppy agar medium containing $20 \%(\mathrm{v} / \mathrm{v})$ inactivated human serum, yeast extract, thymus nucleic acid and other growth supplements for Mycoplasma organisms. This medium would be adequate for most Mycoplasma but not the organism recently isolated by Chanock et al. (1962). The tubes of medium were incubated at $37^{\circ}$ for 2 days before samples were inoculated into chick embryos, the lungs of which were subsequently examined for specific antigen and for EB. If the inoculum had been a mixture of the PAP organism and an EB-producing Mycoplasm organism then a dissociation of the two properties, and an increase in concentration of EB, might have been expected by passage through the sloppy agar medium. Instead the material from the tube inoculated with PAP organism and convalescent serum provoked fewer EB and less antigen than that inoculated with the organism and the serum without antibody to the PAP organism.

Additional evidence that formation of EB is a property of the PAP organism was obtained by examining two other strains-the classical Mac strain and the recent isolate Bethesda PI. 898. These strains were inoculated into eggs and lung sections examined by immunofluorescence and by Giemsa staining. At the same time serial passage of uninfected CE lung was started in eggs taken at random from the batches used for the two strains of PAP organism and passaged in parallel with them. Lung sections from this uninfected series of embryos consistently failed to react by immunofluorescence with human convalescent serum and did not show EB up to the ninth blind passage. On the other hand, both strains of PAP organism showed EB closely resembling those seen with the Hetter strain. The Mac strain required one passage in the chick embryo before typical specific antigen and EB were clearly present. The Bethesda PI. 898 strain (tissue and fluid phase from third passage in 
infected monkey kidney cell culture) gave typical specific antigen in mesobronchi on first inoculation into the chick embryo and small numbers of $\mathrm{EB}$ were seen in association with epithelial cells. In subsequent egg passages specific antigen was seen distributed through the lung sections, with a stained cellular exudate in the lumena of the mesobronchi. In this material very large numbers of EB were seen, not only on the surfaces of mesobronchial cells, but also in association with the collections of inflammatory cells lying free in the mesobronchial lumen and in the parabronchi. On other occasions numerous EB were present but specific antigen was only poorly revealed by immunofluorescence if at all. As this picture differed somewhat from that observed with the Hetter and Mac strains attempts were made to explain it in terms of contamination with bacteria or viruses (influenza, parainfluenza, Sabin B and other simian viruses). These attempts were all negative and in fact the generalized, atypical immunofluorescent staining seemed to be specific as it occurred only with the convalescent and not with acute-phase sera from cases of pneumonia previously shown to have rising antibody titres against the Hetter strain. Further analysis of the behaviour of the Bethesda PI. 898 strain suggested that it grew faster and to a higher titre in the CE lung as compared with the Mac and Hetter strains. Antigen and EB started off in the usual position at the surface of the mesobronchial epithelial cells 4 days after inoculation, but by 6 or 7 days after inoculation (the usual harvesting time) there was deterioration of antigen, general staining of the sections and a widespread distribution of EB and inflammatory cells. Plate 2, figs. 1 to 3, shows various aspects of lung sections from embryos infected with Bethesda PI. 898 strain of PAP organism.

\section{Experiments with Eaton's $\boldsymbol{P} A \boldsymbol{P}$ organism in tissue culture and in cell-free (lifeless) media}

Tissue culture. Several types of tissue or cell culture were tested for their ability to support survival or growth of the PAP organism. They were inoculated with the chick embryo lung suspension infected with the Hetter strain, incubated at $35^{\circ}$ for 7-12 days. Mixtures of the fluid and cellular phases of the cultures were inoculated into chick embryos and tested for antigen. Promising results were obtained with Maitland-type cultures of chick embryo lung and with fragments of infected chick embryo lung on nutrient agar slopes. Monolayer cultures of chick embryo lung and of the FL line of human amnion cells gave poor results, but monolayer cultures of chick entoderm and primary monkey kidney cells were better. No cytopathic effects were observed in these preparations of chick entoderm or monkey kidney cells. Similar results with monkey kidney and chick entoderm tissue cultures have been reported by Chanock et al. (1960) and Gordon et al. (1960).

Cell-free media. Eaton and colleagues (Eaton, 1950a; Eaton \& Liu, 1957) reported failure to grow pleuropneumonia-like organisms from chick embryo material infected with PAP organism, using, presumably, nutrient broth or solid medium with a high serum content. Having found the PAP organism to contain EB and to be sensitive to aurothiomalate we also tried to grow it in sloppy agar and on solid media. The media were supplemented with $20 \%(\mathrm{v} / \mathrm{v})$ heat-inactivated horse, rabbit or human serum free from antibody to the PAP organism; with yeast extract, sodium deoxyribonucleate, staphylococcal extract; bovine serum albumin 
and potassium phosphate (see Klieneberger-Nobel, 1962, for details). Some batches of basal media were obtained from Dr D. G. ff. Edward and were known to support the growth of Mycoplasma. The media were inoculated with suspensions of chick embryo lung infected with the Hetter, Mac or PI. 898 strains, incubated at $37^{\circ}$ and, at various intervals, portions were titrated in chick embryos for their content of PAP organism. The results suggested that the organism was surviving much better at $37^{\circ}$ than previously reported (Eaton et al. 1945)-it was recovered from cultures held at $37^{\circ}$ for 12 days-but unequivocal evidence of multiplication was not obtained. The media used were very similar to those successfully employed by Chanock et al. (1962) except that the sera were inactivated before use. The variables are being investigated further.

\section{DISCUSSION}

The similarities which were already known to exist between Eaton's PAP organism and the Mycoplasma (pleuropneumonia-like) group of organisms are noted in the Introduction and in Table 1. To these may now be added sensitivity to diethyl ether, kanamycin sulphate and sodium aurothiomalate. The last property was not shared by certain viruses (Nigg's pneumonitis virus of mice, influenza A viruses, vaccinia, variola) which are slightly larger or smaller than the PAP organism. On the other hand, grey lung virus of mice was sensitive to sodium aurothiomalate and smears from mouse lung infected with this virus when stained by the intensified Giemsa method showed bodies similar to EB. Various serological investigations have not revealed so far any antigenic relationship between Eaton's organism and Mycoplasma mycoides var. mycoides, M. mycoides var. capri, M. gallinarum, $M$. iners, $M$. gallisepticum, $M$. hominis Type $1, M$. fermentans, or $M$. salvarium (Newnham, Goodburn \& Marmion, unpublished). Preliminary experiments in collaboration with $\operatorname{Dr}$ P. Whittlestone (Department of Veterinary Pathology, Cambridge) do not suggest an antigenic relationship between the organism of enzootic pneumonia of swine and the PAP organism.

The finding in infected chick embryo lung sections stained by the intensified Giemsa method, of small bodies (EB) of coccobacillary shape resembling that of the bodies seen in the inflammatory exudate associated with certain pathogenic mycoplasmas or their cultures requires discussion. The evidence suggests that EB and specific antigen detected by immunofluorescence are two attributes of the same PAP organism. They have been found in the same position in association with the mesobronchial epithelial cells in CE lungs infected with three different strains of the PAP organism (Mac, Hetter (FH) and Bethesda PI. 898) isolated in 1944, 1954 and 1960, respectively. (They have also been found recently in a freshly-isolated Dutch strain sent to us by Dr J. F. Ph. Hers, Leiden, Holland.) They have not been found in lung sections from uninfected chick embryos or from embryos in a series of lungto-lung passages of uninfected material. With the Hetter strain EB and antigen appear in the CE mesobronchus at about the same time, namely 3-4 days after inoculation. Both are suppressed by treatment of the inoculum of the chick embryos with diethyl ether, kanamycin and aurothiomalate. However, a dissociation of the two properties was observed in two situations. When the Hetter strain was titrated in chick embryos it was found that the end-point at which EB were seen in the CE lung sections was 10- or 100-fold lower than that determined by immunofluorescence. 
This might be simply a matter of the sensitivity of the two techniques-small numbers of EB are difficult to identify with certainty. On the other hand, the reverse was found with the Bethesda PI. 898 strain: EB were sometimes seen when antigen was absent. Probably this was because the antigen of the Bethesda PI. 898 strain deteriorated rapidly during the last 2 days of incubation of the embryos. The size of the EB appeared to be larger than that estimated from filtration of the PAP organism. It is possible therefore that EB are a swollen (perhaps degenerate) fraction of the total population of particles of the PAP organism, all of which are demonstrable by immunofluorescence.

There are several possible interpretations of the nature of EB. They might, for example, be protrusions of cytoplasm from cells damaged by virus growth. This is improbable because the cells show slight damage only. EB have the staining qualities of nuclear rather than cytoplasmic material, and similar structures were not seen in mesobronchial cells in the lungs of chick embryos infected with influenza virus. Now that a pleuropneumonia-like organism has been isolated from material infected with the PAP organism (Chanock et al. 1962) the simplest explanation is that EB are the small reproductive cells of the organism growing mainly in the layer of mucus on the surface of the CE mesobronchial cells; a location which offers the advantages of physical support, high external colloid osmotic pressure and a high concentration of diffusible growth factors from the cells.

There is a discrepancy between our findings with CE lung sections stained by Giemsa and those of Donald \& Liu (1959) with thin sections of infected CE trachea in the electron-microscope. These workers saw particles of $150-250 \mathrm{~m} \mu$, sometimes with a thin envelope $350-500 \mathrm{~m} \mu$, inside about $10 \%$ of the epithelial cells, mostly non-ciliated. Particles on the surface of cells were not noted. In comparable material examined in the fluorescence microscope they saw antigen associated with both ciliated and non-ciliated cells. This discrepancy might be resolved if the fluorescent material was mainly on the cell surface and easily removed or distorted during fixation and embedding, and if phagocytosis of material is mainly a function of non-ciliated cells. Clyde (1961) provides support for the view that the PAP organism grows on, rather than in cells.

The finding that the PAP organism is related to the Mycoplasma has other implications which might be investigated with advantage. For example, apart from the grey lung virus of mice, already mentioned, there are other large filterable organisms of uncertain nature that cause pneumonia in animals, infectious pneumonia of pigs (Gulrajani \& Beveridge, 1951; Betts, 1952), virus pneumonia of rats (Vrolijk, Verlinde \& Braams, 1957) which have features in common with the PAP organism. Tests for sensitivity to gold salts and the demonstration of EB and antigen by intensified Giesma staining and immunofluorescence might be useful initial methods for distinguishing from the true viruses a group of organisms with biological properties similar to those of Eaton's organism. Clinically, the behaviour of known Mycoplasma in producing chronic infection in the rodent lung might stimulate a search for persistent infection and chronic damage in the human lung infected with Eaton's PAP organism.

We thank particularly Professor C. L. Oakley (Leeds) for stimulating discussions and other help. Valuable information and gifts of media and sera were received from 
Dr D. G. ff. Edward (Burroughs Wellcome and Co. Ltd.) and from Dr P. Whittlestone and Miss A. Newnham at Cambridge.

We are indebted to Dr Janet Niven (National Institute for Medical Research, London), Professor C. H. Stuart-Harris (Sheffield), Dr K. McCarthy (Liverpool), Dr W. Goldie (Leeds), Dr R. Chanock (Bethesda) and Dr M. D. Eaton (Boston) for virus strains or antisera. Mr J. Hainsworth (Leeds) and Mr R. Pegg (Leeds) helped with photography.

One of us (G. M. G.) is in receipt of an M.R.C. scholarship and the work forms part of a Thesis to be submitted for the Ph.D. degree in the University of Leeds.

\section{REFERENCES}

Andrewes, C. H., KING. H. \& van DEn Ende, M. (1943). Chemotherapeutic experiments with the viruses of influenza A, lymphogranuloma and vaccinia. J. Path. Bact. 55, 173.

ANDrewes, C. H. \& Glover, R. E. (1945). Grey lung virus : an agent pathogenic for mice and other rodents. Brit. J. exp. Path. 26, 379.

Andrewes, C. H. \& Niven, J. S. F. (1953). Action of arsenicals on infection of mice with grey lung virus. J. Path. Bact. 66, 565.

BAUER, D. J. (1958). Chemotherapeutic effect of compounds of copper, rhodium and certain other metals in mice infected with neurovaccinia and ectromelia viruses. Brit. J. exp. Path. 39, 480.

BETTS, A. O. (1952). Respiratory diseases of pigs. V. Some clinical and epidemiological aspects of virus pneumonia of pigs. Vet. Rec. 64, 283.

Bridré, J., Donatien, A. \& Hilbert, D. (1928). Le stovarsol, specifique de l'agalaxie contagieuse du mouton et de la chevre. C.R. Acad. Sci., Paris, 187, 262.

Burnet, F. M. (1936). Influenza virus in the developing egg. 1. Changes associated with the development of an egg-passage strain of virus. Brit. J. exp. Path. 17, 282.

Chanock, R. M., Fox, H. H., James, W. D., Bloom, H. H. \& Mufson, M. A. (1960). Growth of laboratory and naturally occurring strains of Eaton agent in monkey kidney tissue culture. Proc. Soc. exp. Biol., N.Y. 105, 371.

Chanock, R. M., Mufson, M. A., Bloom, H. H., James, W. D., Fox, H. H. \& Kingston, J. R. (1961). Eaton agent pneumonia. J. Amer. med. Ass. 175, 213.

Chanock, R. M., Hayflick, L. \& Barile, M. F. (1962). Growth on artificial medium of an agent associated with atypical pneumonia and its identification as a PPLO. Proc. nat. Acad. Sci., Wash. 48, 41.

Clyde, W. A., Denny, F. W. \& Dingle, J. H. (1960). Fluorescent stainable antibodies to the Eaton agent in human primary atypical pneumonia transmission studies. J. Lab. clin. Med. 56, 799.

Clyde, W. A. (1961). Demonstration of Eaton's Agent in Tissue Culture. Proc. Soc. exp. Biol., N.Y. 107, 715.

Cook, M. K., Chanock, R. M., Fox, H. H., Huebner, R. J., Buescher, E. L. \& Johnson, R. T. (1960). Role of Eaton agent in disease of lower respiratory tract. Evidence for infection in adults. Brit. med. J. i, 905.

Donald, H. B. \& LiU, C. (1959). Cytological studies of chick embryo cells infected with the virus of primary atypical pneumonia. Virology, 9, 24.

Eaton, M. D., Meiklejohn, G. \& van Herick, W. (1944). Studies on the etiology of primary atypical pneumonia. A filterable agent transmissible to cotton rats, hamsters and chick embryos. J. exp. Med. 79, 649.

Eaton, M. D., Meiklejohn, G., van Herick, W. \& Corey, M. (1945). Studies on the etiology of primary atypical pneumonia. II. Properties of the virus isolated and propagated in chick embryos. J. exp. Med. 82, 317.

EAton, M. D. (1950a). Virus pneumonia and pneumonitis viruses of man and animals. Handbuch d. Virusforschung, p. 87. Ed. by R. Doerr and C. Hallauer. Vienna: Springer.

EAton, M. D. (1950b). Action of aureomycin and chloromycetin on the virus of primary atypical pneumonia. Proc. Soc. exp. Biol., N.Y. 73, 24. 
Eaton, M. D. (1954-55). Effect of some newer antibiotics on the agent of primary atypical pneumonia. In Antibiotics Annual 1954-55, p. 1046. Ed. by H. Welch and F. MartiIbanez. New York: Medical Encyclopedia, Inc.

Eaton, M. D. \& Liv, C. (1957). Studies on sensitivity to streptomycin of the atypical pneumonia agent. J. Bact. 74, 784.

Eaton, M. D., Perry, M. E. \& Gocke, I. M. (1957). Effect of nitro-compounds and aldehyde semicarbazones on virus of primary atypical pneumonia. Proc. Soc. exp. Biol., N.Y. 77, 422.

EDward, D. G. FF. (1947). Catarrh of the upper respiratory tract in mice and its association with pleuropneumonia-like organisms. J. Path. Bact. 59, 209.

EDward, D. G. FF. (1954). The pleuropneumonia group of organisms: a review, together with some new observations. J. gen. Microbiol. 10, 27.

Findlay, G. M., Mackenzie, R. D. \& MacCallum, F. O. (1940). Chemotherapeutic experiments in pleuropneumonia organisms in rodents. Brit. J. exp. Path. $21,13$.

FogH, J. \& HACKER, C. (1960). Elimination of pleuropneumonia-like organisms from cell cultures. Exp. Cell Res. 21, 242.

Goodburn, G. M. \& Marmion, B. P. (1962). Investigations of the nature of Eaton's primary atypical pneumonia organism. Proceedings of the Congress on Respiratory Tract Diseases of Virus and Rickettsial Origin, Prague, May 1961. J. Hyg. Epid. Microbiol. Immunol. (in the Press).

Gordon, F. B., Quan, A. L., Cook, M. K., Chanock, R. M. \& Fox, H. H. (1960). Growth of the Eaton agent of primary atypical pneumonia in chick entodermal tissue culture. Proc. Soc. exp. Biol., N.Y. 105, 375.

Gulrajani, T. S. \& Beveridge, W. I. B. (1951). Infectious pneumonia of pigs. Nature, Lond. 167, 856.

Henneguy, P. (1891). Cited in Bolles Lee. The Microtomist's Vade-mecum, p. 184, §370. London (1937): Churchill.

Jungeblut, C. W. (1930-31). Attempts at chemotherapy in experimental poliomyelitis. Proc. Soc. exp. Biol., N.Y. 28, 176.

Klieneberger-Nobel, E. (1962). Pleuropneumonia-like Organisms (PPLO) Mycoplasmataceae. London: Academic Press.

Kolmer, J. A. \& Rule, A. M. (1933-34). A note on the chemotherapy of experimental poliomyelitis of monkeys. Proc. Soc. exp. Biol., N.Y. 31, 50.

Liu, C., Eaton, M. D. \& Heyl, J. T. (1956). Studies on primary atypical pneumonia. Bull. N.Y. Acad. Med. 32, 170.

LIU, C. (1957). Studies on primary atypical pneumonia. I. Localization, isolation, and cultivation of a virus in chick embryos. J. exp. Med. 106, 455 .

Marmion, B. P. \& Goodburn, G. M. (1961). Effect of an organic gold salt on Eaton's primary atypical pneumonia organism and other observations. Nature, Lond. 189, 247.

Mornet, P., Orue, J. \& Marty, J. P. (1951). Note sur le traitement de la péri-pneumonie bovine par la pénicilline, la streptomycine et certains dérivés sulfamidés. Action comparée avec le novarsénobenzol. Bull. Acad. vét. Fr. 24, 213.

Monton, H. E. (1958). The pleuropneumonia and pleuropneumonia-like organisms. Bacterial and Mycotic Infections of Man, pp. 563-81. Ed. R. J. Dubos, 3rd ed. London: Pitman Medical.

NrGG, C. \& EATon, M. D. (1944). Isolation from normal mice of a pneumotropic virus which forms elementary bodies. J. exp. Med. 79, 497 .

Pearse, A. G. E. (1960). Histochemistry, Theoretical and Applied, pp. 13-24, 2nd ed. London: Churchill.

Pollock, M. E., Kenny, G. E. \& Syverton, J. T. (1960). Isolation and elimination of pleuropneumonia-like organisms from mammalian cell cultures. Proc. Soc. exp. Biol., N.Y. 105, 10.

Richardson, G. M. (1941). Preservation of liquid complement serum. Lancet, ii, 696.

SABIN, A. B. \& WARREn, J. (1940). The therapeutic effectiveness of a practically non-toxic new compound (calcium aurothiomalate) in experimental, proliferative, chronic arthritis of mice. Science, $\mathbf{9 2 ,} \mathbf{5 3 5}$. 
Taylor, R. M. \& Chialvo, R. J. (1942). Simplified technic for inoculating into amniotic sac of chick embryos. Proc. Soc. exp. Biol., N.Y. 51, 328.

van Herick, W. \& Eaton, M. D. (1945). An unidentified pleuropneumonia-like organism isolated during passage in chick embryos. J. Bact. 50, 47.

Vrolijk, H., Verlinde, J. D. \& BraAms, W. G. (1957). Virus pneumonia (snuffling disease) in laboratory rats and wild rats due to an agent probably related to grey lung virus in mice. Leeuwenhoek ned. Tijdschr. 23, 173.

\section{EXPLANATION OF PLATES}

\section{Prate 1}

Fig. 1. Medium power view of the epithelial cell layer and lumen in mesobronchus of chick embryo. Acetone-fixed frozen section, Hetter strain, stained with human convalescent serum and fluoresceinlabelled globulin. Collections of brightly fluorescing particles are present inside or on the surfaces of the epithelial cells and a few particles are free in the lumen.

Fig. 2. Next serial section to that shown in Fig. 1. High-power view of epithelial cell layer and lumen in the same invagination of the chick embryo mesobronchus but in a Giemsa-stained section. Numerous EB are present in a similar position to the specific antigen in Fig. 1. Acetone-fixed frozen section. Intensified Giemsa staining. Polystyrene (DePeX) mount.

Fig. 3. High-power view of the epithelial cell layer in an uninfected chick embryo mesobronchus. A faint stippling marks the edge of the cell cytoplasm and the layer of mucus can be seen at the cell edge and beyond it. EB are not present. Acetone-fixed frozen section. Intensified Giemsa stain. Glycerol-buffer mount.

\section{Plate 2}

Fig. 1. Low-power view of chick embryo lung mesobronchus infected with 'Bethesda PI. 898' strain of PAP organism (4th egg passage $10^{-2}$ diln.). Inflammatory cells are present in the lumen. Unfixed frozen section. Intensified Giemsa staining. Glycerol-buffer mount.

Fig. 2. Low-power view of the same mesobronchus as in Fig. 1, but in an adjacent section stained by immunofluorescence. The specific antigen is not only present in the vicinity of the surface of the mesobronchial epithelial cells but also apparently in the inflammatory cells lying free in the lumen. Acetone-fixed frozen section stained with human PAP serum pool and fluorescein-labelled antihuman globulin.

Fig. 3. High-power view of the epithelial cell edge of a chick embryo lung mesobronchus infected with the 'Bethesda PI. 898' strain of PAP organism (3rd egg passage). EB can be seen in a layer on the surface of the epithelial cells, lying free in the lumen and also within the cytoplasm of a cell which is part of the exudate in the mesobronchial lumen. Unfixed frozen section, intensified Giemsa staining, Glycerol-buffer mount. 

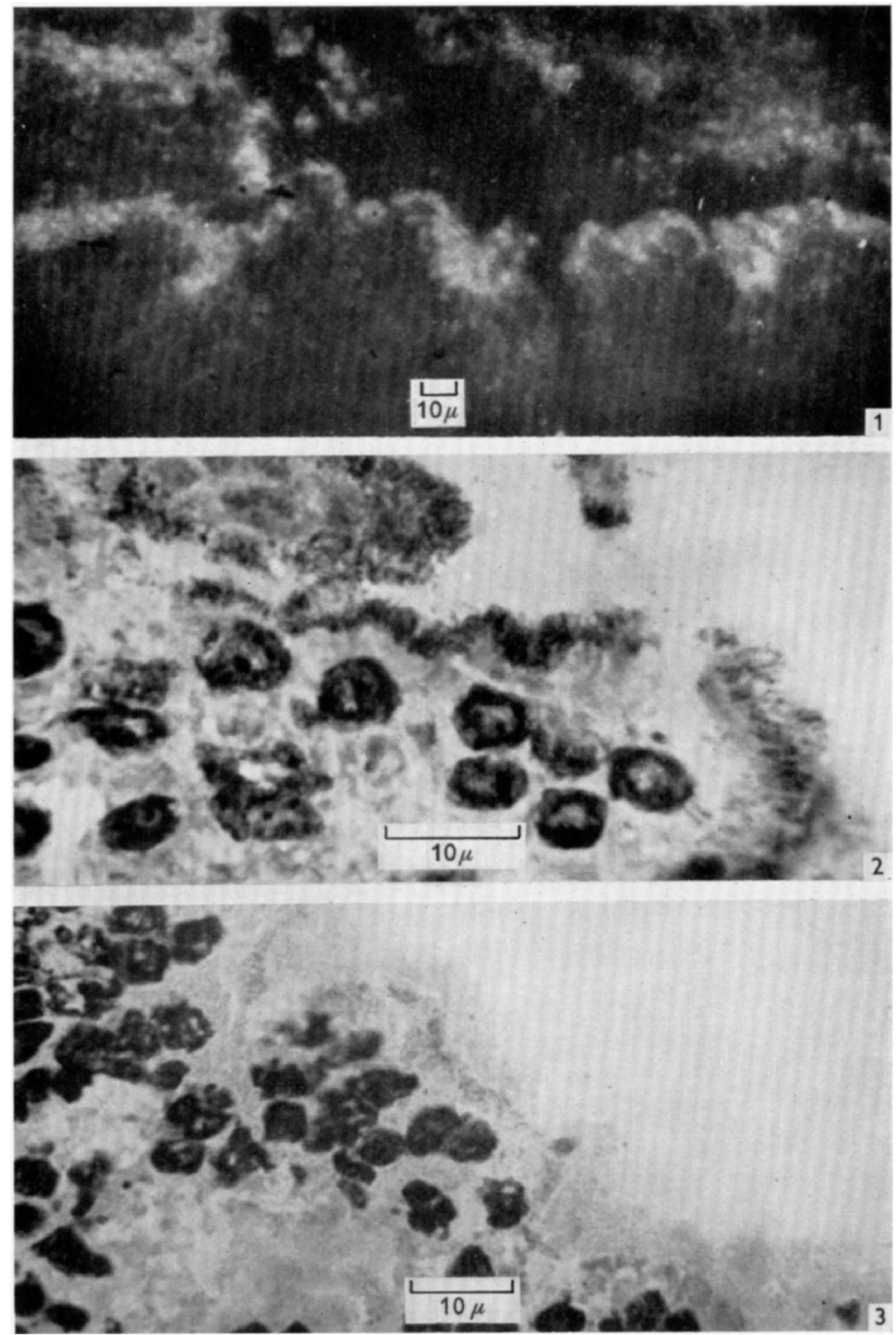
Journal of General Microbiology, Vol. 29, No. 2

Plate 2
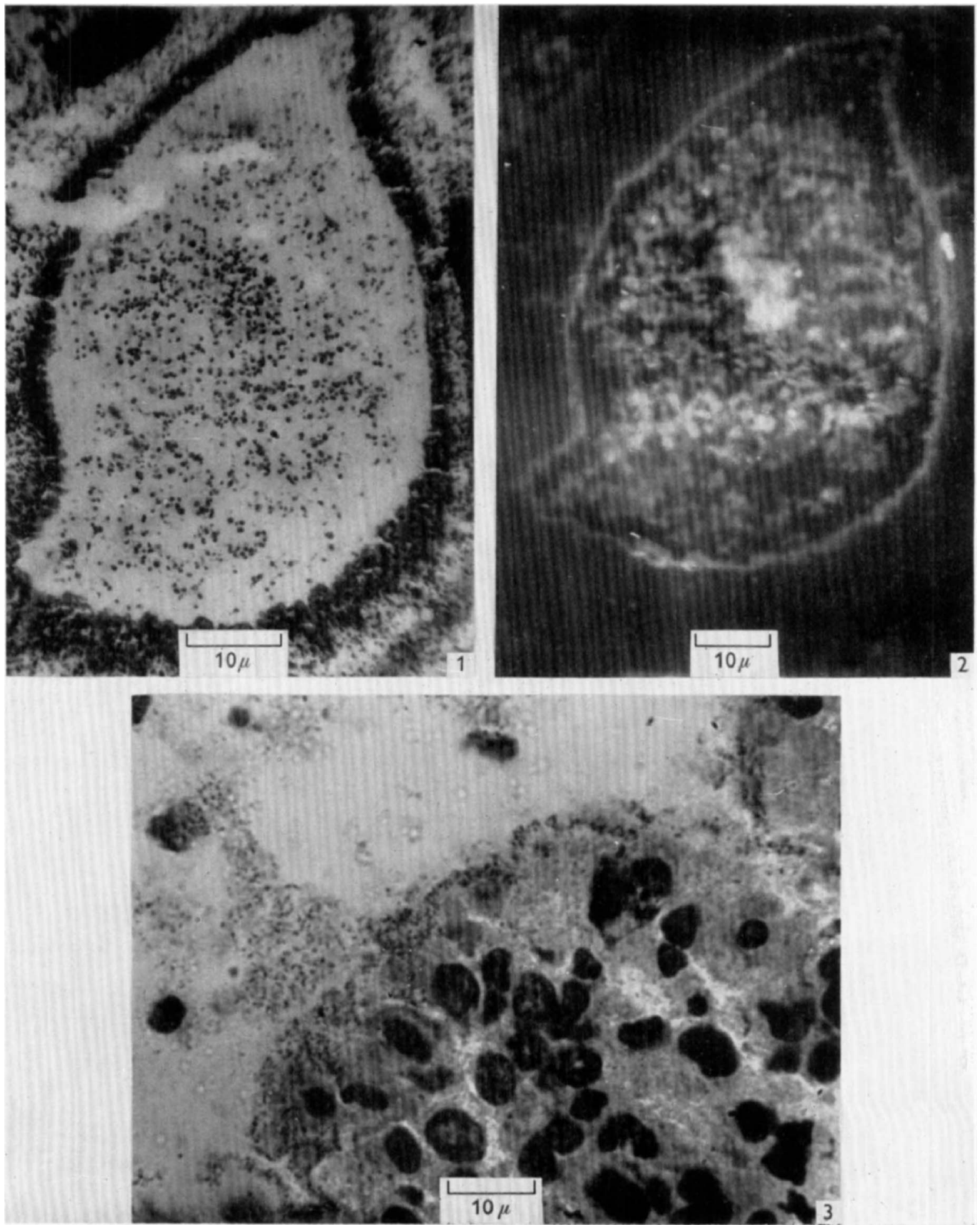

G. M. GOODBURN AND B. P. MARMION 